\title{
Influence of Pulmonary Valve Function Preservation Technique for Tetralogy of Fallot Repair on Right Ventricular Performance in Children
}

\author{
Hamdy Ahmed Singab, PhD \\ Department of Cardiovascular and Thoracic Surgery, Faculty of Medicine, Ain Shams University, Ain Shams University Hospitals, \\ Abbasia square, Cairo, Egypt
}

\section{ABSTRACT}

Background: Right ventricular (RV) ejection fraction may remain normal or even high despite significant impairment of RV myocardial performance in cases of total repair for tetralogy of Fallot (TOF). The aim of this study is to evaluate the influence of pulmonary valve function preservation (PVFP) versus monocuspid transannular patch augmentation (MTAPA) surgical strategies for Fallot repair on postoperative RV performance.

Methods: This retrospective study enrolled all patients $(\mathrm{N}=480)$ who had TOF repaired at our center over a period of 7 years (March 2012 to January 2019). Group I included 377 patients $(78.5 \%)$ who underwent TOF repair with MTAPA, and group II included 103 patients $(21.5 \%)$ who underwent TOF repair with PVFP, which included all patients with pulmonary valve sparing with limited sub- or supravalvular patch. Patients' preoperative and postoperative echocardiography and other parameters (ventilation time, intensive care unit [ICU] stay duration, and RV myocardial performance index [RVMPI]) were recorded to evaluate RV function.

Results: We observed a significant statistical difference in the postoperative course between groups I and II, with excellent midterm outcomes for group II. A remarkable significant improvement of RVMPI took place in group II versus group I $(P<.0001)$, as well as a significant decline in pulmonary regurgitation progression $(P<.0001)$. The immediate postoperative RVMPI in group I $(0.79 \pm 0.63)$ versus that in group II $(0.36 \pm 0.17)$ was significantly higher $(P<.0001)$, as was the late postoperative RVMPI (group I, $0.64 \pm 0.25$; group II, $0.49 \pm 0.17 ; P<0001)$. The postoperative RV outflow tract was decreased in group II versus group I. Group II had a significantly shorter duration on mechanical ventilation and in the ICU and less need for inotropes.

Conclusion: We conclude that TOF repair patients have excellent RV myocardial performance with the PVFP surgical strategy in comparison with MTAPA.

Received February 10, 2020; received in revised form March 10, 2020; accepted March 10, 2020.

Correspondence: Hamdy Abmed Singab, PbD, Department of Cardiovascular and Thoracic Surgery, Faculty of Medicine, Ain Shams University, Ain Shams University Hospitals, Abbasia Square, Cairo, Egypt; 00201001008859 (e-mail: hamdi_singab@hotmail.com).

\section{INTRODUCTION}

Tetralogy of Fallot (TOF), a spectrum of different pathologies and not a single disease, ranges from mild to severe. Different surgical strategies have been used to release right ventricular outflow tract (RVOT) obstruction during repair of tetralogy of Fallot, including monocuspid transannular patch augmentation (MTAPA) (monocuspid with polytetrafluoroethylene [PTFE]; pericardial membrane or monocuspid homograft; Contegra) and pulmonary valve function preservation (PVFP) (pulmonary valve sparing with limited sub- or supravalvular augmentation patch) [Kirklin 1992].

Long-term clinical outcomes have shown that patients who underwent MTAPA developed severe pulmonary regurgitation (PR), which led to right ventricular dysfunction, arrhythmia, and poor functional status, progressing to death. Patients undergoing repair of TOF with MTAPA had significantly more RV dilation and dysfunction over time than those with PVFP. MTAPA had a higher incidence of severe chronic PR than PVFP, and the severe chronic PR after MTAPA progressively affected RV myocardial performance, resulting in irreversible RV dysfunction [Awori 2013; Rebergen 1993; Yoo 2012].

The current trend among different pediatric cardiac surgery centers favors PVFP to avoid the deleterious consequences of $\mathrm{PR}$ and $\mathrm{RV}$ dysfunction. The RV adaptation to PVFP is still a subject of investigation and research [Awori 2013; Mahran 2016].

$\mathrm{RV}$ myocardial performance (RVMP) is the best contemporary predictor of morbidity and mortality for perioperative risk stratification of patients undergoing TOF repair. Few studies have assessed the value of RVMP echocardiographic evaluation in these patients. Puchalski et al [2007] found that echocardiography was the most accurate and reliable tool to detect RVMP and RV dysfunction [Eidem 2000; Carminati 2015; Bonnemains 2012; Suzuki 1991].

A majority of patients undergoing TOF repair are at risk of RV dysfunction and progressive RV dilatation, so cardiac dimensions, volume, and performance assessment are mandatory. However, tricuspid annular plane systolic excursion (TAPSE) and peak systolic velocity, which are used most often to evaluate RV function, have been found to be undependable variables for RV performance assessment after TOF repair. Recent advances in echocardiography (3- and 4-dimensional tissue Doppler) suggest the RV myocardial performance index (RVMPI), or Tei index, as a simple reproducible tool 
Table 1. Comparison of the Preoperative Demographics between Groups I and II*

\begin{tabular}{lccc}
\hline & $\begin{array}{c}\text { Group I } \\
(\mathrm{n}=377)\end{array}$ & $\begin{array}{c}\text { Group II } \\
(\mathrm{n}=103)\end{array}$ & $P$ \\
\hline Variable & $260 / 117$ & $60 / 43$ & .07 \\
Age (mo) & $19 \pm 8$ & $18 \pm 9$ & .06 \\
Weight (kg) & $8.8 \pm 4.3$ & $7.8 \pm 3.4$ & .12 \\
Body surface area (m2) & $0.43 \pm 0.13$ & $0.41 \pm 0.11$ & .15 \\
Preoperative O2 saturation (\%) & $75 \pm 6.3$ & $74.2 \pm 4.9$ & .23 \\
Preoperative hemoglobin (mmol/L) & $125 \pm 34$ & $123 \pm 43$ & .61 \\
Previous modified Blalock-Taussig & $65(17.2)$ & $18(17.4)$ & .95 \\
shunt & & & \\
Hemoglobin (g/dL) & $32 \pm 5$ & $31.7 \pm 7.5$ & .63 \\
Preoperative RVOT gradient (mmHg) & $95 \pm 6.25$ & $94 \pm 5.73$ & .14 \\
RVEDD (mm) & $33 \pm 5.62$ & $32 \pm 6.02$ & .12 \\
LVEDD (mm) & $27.86 \pm 5.6$ & $27.4 \pm 6.4$ & .47 \\
LVESD (mm) & $16.32 \pm 5.19$ & $16.5 \pm 1.02$ & .72 \\
IVCT (ms) & $44.9 \pm 4.65$ & $45.6 \pm 4.62$ & .17 \\
IVRT (ms) & $40.13 \pm 3.21$ & $41.28 \pm 6.21$ & .07 \\
RVET (ms) & $184.7 \pm 7.74$ & $185.5 \pm 6.21$ & .33 \\
EF (\%) & $64 \pm 12$ & $63 \pm 11$ & .44 \\
RVMPI & $0.46 \pm 0.16$ & $0.47 \pm 0.15$ & .57 \\
\hline
\end{tabular}

*Data are mean \pm SD or $\mathrm{n}(\%)$ unless noted otherwise. RVEDD indicates right ventricular end diastolic diameter.

for evaluating RVMP. RVMPI incorporates both systolic and diastolic ventricular performance and correlates well with changes in clinical status after TOF repair. RVMPI is independent of RV geometry, heart rate, or RV preload, so it is particularly beneficial in correct assessment of RVMP [Lee 2015; Mahran 2016; Su 2007; Grignola 2006; Tei 1996; Roberson 2007; Rudski 2010].

The main purpose of this study is to evaluate the postoperative RVMP changes in patients undergoing TOF repair with MTAPA versus PVFP surgical strategies to release RVOT obstruction.

\section{METHODS}

\section{Patients}

This retrospective study involved all patients who had TOF repaired at our center over a period of 7 years (March 2012 to January 2019). The study was approved by the local ethics committee in accordance with the Helsinki Declaration on clinical research involving human beings. Legal guardians of the operated infants gave informed consent before the operative procedures. Patients were classified into 2 groups. Group I included patients who underwent TOF repair with MTAPA,
Table 2. Comparison of Operative Variables between Groups I and II

\begin{tabular}{lccc}
\hline Variable & Group I $(\mathrm{n}=377)$ & Group II $(\mathrm{n}=103)$ & $P$ \\
\hline Cross-clamp time (min) & $57 \pm 19$ & $59 \pm 16$ & .32 \\
Bypass time (min) & $86 \pm 21$ & $89 \pm 11$ & .16
\end{tabular}

and group II included patients who underwent TOF repair with PVFP, including all patients with pulmonary valve sparing with limited sub- or supravalvular patch. Patients with other congenital heart disease or needing emergency surgery were excluded from the study.

\section{Surgical Techniques}

All patients receive general anesthesia. Any administration of water or milk is suspended for 6 hours. Midazolam 0.07 to $0.1 \mathrm{mg}$ is administered through peripheral vein $20 \mathrm{~min}$ utes before entering the cardiac theater; if peripheral venous cannulation fails, anesthesia is used with titrated doses of Sevoflurane $4 \%$ to cannulate the external jugular vein or put in a central venous line. Immediately after venous access, the patient receives plasma expander, $10 \mathrm{~mL} / \mathrm{kg}$, and $\mathrm{NaHCO}_{3}$, $2 \mathrm{mEq} / \mathrm{kg}$. All patients receive Ketamine, 1 to $2 \mathrm{mg} / \mathrm{kg}$ slowly, and a slow bolus of Midazolam, $2 \mathrm{mg}$, and Rocuronium, 1 to $2 \mathrm{mg} / \mathrm{kg}$, for induction and intubation. Endotracheal intubation is performed immediately after arterial cannulation. After intubation, electrocardiography, invasive blood pressure, central venous pressure, $\mathrm{SpO}_{2}$, core and peripheral temperature, and urine output measurements are taken. In this study, all patients were operated under general anesthesia and standard median sternotomy. Heparin is used to meet activated clotting time $>450$ seconds. Cardiopulmonary bypass starts through direct aortobicaval cannulation, under moderate hypothermia $\left(28^{\circ} \mathrm{C}\right)$, followed by aortic cross clamping, myocardial preservation with antegrade enriched blood cardioplegia, tapping of caval cannula, and right atriotomy [Karl 1992; Koestenberger 2012; Geva 2004].

Operative assessment of the degree of RVOT obstruction and aortic overriding after tricuspid valve retraction are followed by transatrial resection of the infundibular obstruction, then pulmonary arteriotomy. The pulmonary valve is inspected to determine its morphology. Any pulmonary commissural fusion is freed, followed by pulmonary valvotomy. The pulmonary annulus is measured with a Hegar dilator with respect to age and weight, and the degree of infundibular obstruction is assessed through the pulmonary valve. If the pulmonary annulus is small or the infundibulum has long tubular stenosis, an extra infundibular resection is done through an infundibular incision. Pulmonary arteriotomy and RV ventriculotomy repair are done via MTAPA (monocuspid with polytetrafluoroethylene [PTFE]; pericardial membrane or monocuspid homograft; Contegra) [Bacha 2001; Gatzoulis 2000; Yoo 2012].

If the Hegar dilator passes smoothly through the pulmonary annulus, PVFP is used, and the RV infundibular 
pulmonary arteriotomy is closed with a supravalvular augmentation patch. Our PVFP technique preserves the pulmonary

Table 3. Comparison of Postoperative Variables between Groups I and II*

\begin{tabular}{|c|c|c|c|}
\hline Variable & $\begin{array}{c}\text { Group I } \\
(\mathrm{n}=377)\end{array}$ & $\begin{array}{c}\text { Group II } \\
(n=103)\end{array}$ & $P$ \\
\hline Inotropes duration (h) & $122 \pm 62$ & $68 \pm 24$ & $<.0001$ \\
\hline Inotropes number & $3.7 \pm 0.7$ & $1.7 \pm 0.7$ & $<.0001$ \\
\hline Ventilation time $(\mathrm{h})$ & $75 \pm 24.7$ & $28.8 \pm 4.5$ & $<.0001$ \\
\hline ICU stay (d) & $7.8 \pm 3.6$ & $4.5 \pm 2.5$ & $<.0001$ \\
\hline Hospital stay (d) & $14.3 \pm 3.7$ & $8.4 \pm 4.5$ & $<.0001$ \\
\hline Pleural effusion & $53(14)$ & $6(6.1)$ & .03 \\
\hline Pericardial effusion & $42(11.1)$ & $1(1.03)$ & .001 \\
\hline Arrhythmia & $83(22)$ & $21(21)$ & .83 \\
\hline Acute renal failure & $35(9.3)$ & $2(2.06)$ & .02 \\
\hline Temporary dialysis & $11(2.9)$ & $1(1.03)$ & .28 \\
\hline Neurological complications & $19(5)$ & $2(2.06)$ & .19 \\
\hline Reopening & $20(5.3)$ & $2(2.06)$ & .16 \\
\hline Death & $4(1.06)$ & $1(1.03)$ & .97 \\
\hline \multicolumn{4}{|c|}{ Immediate postoperative echocardiography data (at discharge) } \\
\hline Postoperative RVOT (mmHg) & $19.2 \pm 9.9$ & $15 \pm 4.3$ & $<.0001$ \\
\hline $\operatorname{RVEDD}(\mathrm{mm})$ & $36 \pm 6.32$ & $32 \pm 4.02$ & $<.0001$ \\
\hline $\operatorname{LVEDD}(\mathrm{mm})$ & $27.86 \pm 5.6$ & $27.4 \pm 6.4$ & .47 \\
\hline LVESD (mm) & $26.5 \pm 3.21$ & $25.9 \pm 6.31$ & .19 \\
\hline IVCT (ms) & $58.2 \pm 10.5$ & $53.5 \pm 6.43$ & $<.0001$ \\
\hline IVRT (ms) & $49.34 \pm 15.69$ & $45.2 \pm 9.28$ & .0007 \\
\hline RVET (ms) & $263 \pm 29.3$ & $275.9 \pm 9.64$ & $<.0001$ \\
\hline $\mathrm{EF}$ & $62.5 \pm 8.2$ & $63 \pm 5.3$ & .55 \\
\hline RVMPI & $0.79 \pm 0.63$ & $0.36 \pm 0.17$ & $<.0001$ \\
\hline PR (moderate to severe) & $113(29.9)$ & $10(10)$ & $<.0001$ \\
\hline \multicolumn{4}{|c|}{ Late postoperative echocardiography data (6-year follow-up ) } \\
\hline RVOT gradient $(\mathrm{mmHg})$ & $18.3 \pm 5.6$ & $16.2 \pm 7.3$ & .001 \\
\hline $\operatorname{RVEDD}(\mathrm{mm})$ & $38 \pm 4.22$ & $34 \pm 5.1$ & $<.0001$ \\
\hline $\operatorname{LVEDD}(\mathrm{mm})$ & $29.36 \pm 6.2$ & $28.1 \pm 4.4$ & .05 \\
\hline $\operatorname{LVESD}(\mathrm{mm})$ & $28.2 \pm 3.41$ & $27.6 \pm 2.51$ & .09 \\
\hline IVCT (ms) & $71.3 \pm 5.5$ & $65.1 \pm 4.03$ & $<.0001$ \\
\hline IVRT (ms) & $86.2 \pm 10.5$ & $64.5 \pm 6.43$ & $<.0001$ \\
\hline RVET (ms) & $248 \pm 32.5$ & $265.1 \pm 8.34$ & $<.0001$ \\
\hline $\mathrm{EF}$ & $63 \pm 6.2$ & $65 \pm 3.7$ & .001 \\
\hline RVMPI & $0.64 \pm 0.25$ & $0.49 \pm 0.17$ & $<.0001$ \\
\hline PR (moderate to severe) & $150(39.8)$ & $12(11.6)$ & $<.0001$ \\
\hline
\end{tabular}

*Data are mean \pm SD or $\mathrm{n}(\%)$. RVEDD indicates right ventricular end diastolic diameter. valve and annulus to achieve a low postoperative pressure gradient and avoids the harmful effects of pulmonary regurgitation (PR) on RV, resulting in better RV performance. Some patients undergo aggressive valvotomy to keep the pulmonary annulus. In severe infundibular stenosis with adequate pulmonary annulus after valvotomy, aggressive infundibular resection is performed via $\mathrm{RV}$ ventriculotomy, necessitating 2 patch closures, one above and one below the annulus [Frigiola 2004; Weidemann 2002].

The ventricular septal defect is closed via right atriotomy with a Gortex patch using interrupted running sutures on Teflon pledgets with 5-0 polyproline sutures. After closing the right atriotomy, deairing, aortic declamping, and smoothing of the cardiopulmonary bypass under inotropic support are done. The patient is transferred to the ICU [Yoo 2012; Lozano-Balseiro 2019].

All patients had postoperative echocardiography in the ICU, before discharge, and at postoperative follow-ups. The postoperative echocardiography data reported here were obtained at discharge and 6-year follow-up.

\section{Outcome Measurement}

Basic preoperative demographic data (age, sex, body surface area, and saturation), clinical data, and laboratory data were collected and evaluated. Patients' pre- and postoperative echocardiographic data were recorded, including preoperative RVOT peak pressure gradient, isovolumetric contraction time (IVCT) (milliseconds), isovolumetric relaxation time (IVRT) (milliseconds), RV ejection time (RVET) (milliseconds), ejection fraction (EF), and RVMPI. Also recorded were patients' previous modified Blalock-Taussig shunt, operative variables (cross-clamp and bypass times), and postoperative variables (inotrope number and duration, ventilation time, duration of ICU and hospital stay, pleural effusion, pericardial effusion, arrhythmia, acute renal failure, temporary dialysis, or neurologic complications).

All patients had preoperative and postoperative transthoracic echocardiography with a 2 - to $4-\mathrm{MHz} 4 \times$ matrix probe, including 2-dimensional 4-chamber, then a scan view with tissue Doppler speed from 100 to $150 \mathrm{~mm} / \mathrm{s}$. For each cardiac cycle, we measured the interval from the $\mathrm{R}$ wave to the onset of A wave of the next cardiac cycle. The duration from the beginning to the end of the RV outflow is defined as RVET, and the duration from the end to the start of the tricuspid inflow is calculated as the sum of IVCT and IVRT. All parameters were calculated in 3 to 6 consecutive heart cycles, and the average value was recorded. RVMPI was calculated by the following formula [Grignola 2006; Rudski 2010; Tei 1996; Helbing 1996]:

$$
\text { RVMPI }=[(\mathrm{RV}-\mathrm{IVCT})+(\mathrm{RV}-\mathrm{IVRT})] / \text { RVET } .
$$

\section{Data Analysis}

In our retrospective study, the lowest sample size (n) is 95 to detect whether the stated difference exists between the 2 groups, calculated by

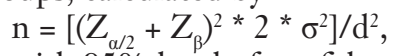

with $95 \%$ level of confidence, $80 \%$ power. $Z_{\alpha / 2}$ is the critical value of the normal distribution at $\alpha / 2=1.96$ for level of 
confidence $95 \%$, and $\alpha$ is $0.05 . Z_{\beta}$ is the critical value of the normal distribution, 0.84 for power of $0.80, \beta$ is 0.2 , and $d$ is the difference detected.

Variables collected from the present study are expressed as number and percentage, mean \pm standard deviation (SD), or median and interquartile range. The comparative analysis of the variables among patient groups was achieved by Student's $t$ test, Fisher's exact test, or Mann-Whitney U test as appropriate. $P$ Values $<.05$ indicate statistical significance. Statistical results were calculated using SPSS version 20 (IBM).

\section{RESULTS}

In this retrospective study, 480 patients fulfilled inclusion criteria for TOF repair in our center: 377 underwent TOF repair with MTAPA in group I (78.5\% of all patients), and 103 underwent TOF repair with PVFP in group II $(21.5 \%$ of all patients). Basic demographic, clinical, and echocardiographic criteria were compared between groups, and differences were statistically nonsignificant (Table 1). Operative values showed no significant differences between groups I and II (Table 2). Significant differences were found in the postoperative ICU course, with excellent midterm outcomes for patients of group II (PVFP technique).

There was a remarkable significant improvement of RVMPI in group II compared with group I $(P<.0001)$, as well as a significant decline of PR progression $(P<.0001)$. Postoperative RVOT was much decreased in group II versus group I. The immediate postoperative RVMPI in group I $(0.79 \pm 0.63)$ in comparison to that in group II $(0.36 \pm 0.17)$ was significantly higher $(P<.0001)$, as was the late postoperative RVMPI in group I $(0.64 \pm 0.25$ versus group II, 0.49 $\pm 0.17 ; P<.0001)$. The immediate postoperative PR in group I $(29.9 \%)$ in comparison to that in group II $(10 \%)$ was significantly higher $(P<.0001)$, as was the late postoperative PR (group I, 39.8\%; group II, $11.6 \%$; $P<0.0001$ ). The immediate postoperative RVOT gradient in group I $(19.2 \pm 9.9$ $\mathrm{mmHg})$ in comparison to that in group II $(15 \pm 4.3 \mathrm{mmHg})$ was significantly higher $(P<.0001)$, as was the late postoperative RVOT gradient (group I; $18.3 \pm 5.6 \mathrm{mmHg}$; group II, $16.2 \pm 7.3 \mathrm{mmHg} ; P=.001$ ). The postoperative left ventricular end diastolic diameter (LVEDD) and left ventricular end systolic diameter (LVESD) values showed no significant difference between groups (Table 3).

Group II had significantly shorter duration on ventilation and ICU stay, less need for inotropes postoperatively, less PR progression, and better RVMPI than group I; the remaining postoperative values showed no significant difference between groups. Postoperative ICU stay in group I (7.8 \pm 3.6 days $)$ compared with that in group II $(4.5 \pm 2.5$ days $)$ was significantly longer $(P<.0001)$. There was a significant increased demand for more inotropes for longer duration in group I versus group II $(P<.0001)$ : postoperatively, group I inotrope number and duration $(3.7 \pm 0.7$ and $122 \pm 62$ hours, respectively) were higher than in group II $(1.7 \pm 0.7$ and 68 \pm 24 ) (Table 3).

\section{DISCUSSION}

Currently, PVFP use in pediatric cardiac surgery is increasing for patients undergoing TOF repair. MTAPA or PVFP techniques have similar early postoperative functional status improvement, as well as low rates of reopening or reintervention. The long-term injurious effect of MTAPA's chronic PR on RV performance has become well known during the last 2 decades. Thus, different pediatric cardiac surgery centers have recently turned to PVFP to decrease the degree of postoperative PR and its long-term effects [Singh 1998; Gatzoulis 2000; Geva 2004].

We report 7 years of experience with 103 patients who underwent TOF repair with PVFP. Postoperative RVMPI $(0.36 \pm 0.17)$ increased significantly to the late postoperative period $(0.49 \pm 0.17)$ in comparison to the 377 patients who underwent TOF repair with MTAPA $(0.79 \pm 0.63$ postoperative to $0.64 \pm 0.25$ late postoperative; $P<.0001)$.

Our study results are in agreement with the study of Song et al [2015], who demonstrated RVMPI as a predictor of RV dysfunction after TOF repair. Koestenberger et al [2012] found that TAPSE after repair of TOF had an overall accuracy of $<80 \%$, in comparison to RVMPI's overall accuracy of $95 \%$, in RV dysfunction detection.

During our 7-year follow-up, patients who underwent TOF repair with PVFP showed significant declines in immediate and late postoperative PR (10\% and $11.6 \%$, respectively) compared with MTAPA $(29.9 \%$ and $39.8 \% ; P<.0001)$. The postoperative RVOT gradient of both surgical techniques significantly decreased from the preoperative RVOT gradient, but both early and late postoperative RVOT gradients were significantly decreased in PVFP versus MTAPA.

Although increasing clinical and echocardiographic evidence confirms the benefits of PVFP on RV performance, studies on this issue are not common. In the largest series, Frigiola et al [2004] evaluated the long-term effects of MTAPA on chronic PR. They studied 124 patients undergoing TOF repair with MTAPA at the Heart Hospital (London). They divided the patients into 3 groups: group I (33 patients) had mild PR, group II (22 patients) had moderate PR, and group III (69 patients) had severe PR. Patients with severe PR had a higher incidence of RV dysfunction and reduced RVMPI. They found that MTAPA resulted in severe PR that ended with ventricular dysfunction on long-term follow-up after TOF repair [Frigiola 2004].

Our study results are in agreement with the study of Lozano-Balseiro et al [2019] (Congenital and Structural Heart Disease Research Group, La Coruña, Spain). They investigated 42 patients undergoing TOF repair with PVFP. PVFP showed good early and midterm results on RVMPI, PR progression, and RVOT obstruction. The effect of PVFP on RVMPI has been neglected by pediatric cardiac surgeons, but increasing data support PVFP's importance in patients undergoing TOF repair to achieve good long-term outcomes [Lozano-Balseiro 2019; Geva 2004].

In our series, the early and late postoperative LVEDD and LVESD values showed no significant difference between groups. Early EF showed no significant difference, but late 
postoperative EF was significantly better in PVFP compared with MTAPA $(P=.001)$. However, Schwerzmann et al [2007] reported no value of RV EF in detection of the degree of RV performance and a negative relationship between RVMPI and RV EF in patients with repaired TOF. Selly et al [2015] reported no relation of RVMPI values and RV EF in their patients with TOF repair. Eidem et al [2000] reported no relationship between the degree of postoperative deterioration of RVMPI and RV volume overload in their patients who underwent MTAPA [Frigiola 2004; Karl 1992; Weidemann 2002]. In our series, there was no significant difference in postoperative arrhythmia between MTAPA (22\%) and PVFP (21\%). Gatzoulis et al [2000] reported that MTAPA was related to evolution of ventricular dysrhythmia and unexpected death after TOF repairs.

Although in our study, preoperative patient weight and previous shunt had no significant difference on the postoperative values in morbidity and mortality, Karl et al [1992] reported significantly lower mortality and morbidity rates when they delayed TOF repair in their patients, placing a palliative shunt and waiting until patients weighed $\geq 8 \mathrm{~kg}$ [Weidemann 2002]. In our series, the PVFP group had significantly shorter duration on mechanical ventilation and in the ICU and less need for inotropes postoperatively versus MTAPA $(P<.0001)$.

\section{Limitations}

RV myocardial performance and RV dysfunction in patients undergoing TOF repair with PVFP and MTAPA were evaluated clinically by transthoracic echocardiography tissue Doppler, but the data analysis was angle dependent, which could influence the global RV strain measurements. To overcome this limitation, we need to design a new prospective study examining patients with TOF repair by PVFP and MTAPA for a longer follow-up period, incorporating cardiac magnetic resonance imaging at regular yearly intervals. Because the number of patients in our series is relatively small for a multivariate analysis, we propose that the number of patients in this future study be done in a larger population.

\section{Conclusion}

In summary, we recommend the PVFP technique for patients undergoing TOF repair to optimize clinical outcome, with a very few operative deaths and acceptable reoperation rates. Our study demonstrates that the RVMPI is a long-term outcome determinant of TOF repair. Our series demonstrates the role of PVFP in decreasing PR progression, preserving RV function, and reducing the incidence of postoperative dysrhythmia. Moreover, PVFP reduces the financial cost, as it decreases hospital stays, ICU stays, and the need for inotropes.

\section{REFERENCES}

Awori MN, Leong W, Artrip JH, O’Donnell C. 2013. Tetralogy of Fallot repair: Optimal z-score use for transannular patch insertion. Eur J Cardio-Thorac Surg 43:483-486.
Bacha EA, Scheule AM, Zurakowski D, et al. 2001. Long-term results after early primary repair of tetralogy of Fallot. J Thorac Cardiovasc Surg 122:154-161.

Bonnemains L, Stos B, Vaugrenard T, Marie PY, Odille F, Boudjemline Y. 2012. Echocardiographic right ventricle longitudinal contraction indices cannot predict ejection fraction in post-operative Fallot children. Eur Heart J Cardiovasc Imaging 13:235-242.

Carminati M, Pluchinotta FR, Piazza L, et al. 2015. Echocardiographic assessment after surgical repair of tetralogy of fallot. Front Pediatr 3:3.

Eidem BW, O'Leary PW, Tei C, Seward JB. 2000. Usefulness of the myocardial performance index for assessing right ventricular function in congenital heart disease. Am J Cardiol 86:654-658

Frigiola A, Redington AN, Cullen S, Vogel M. 2004. Pulmonary regurgitation is an important determinant of right ventricular contractile dysfunction in patients with surgically repaired tetralogy of Fallot. Circulation 110(suppl 2):153-157.

Gatzoulis MA, Balaji S, Webber SA, et al. 2000. Risk factors for arrhythmia and sudden cardiac death late after repair of tetralogy of Fallot: A multicentre study. Lancet 356:975-981.

Geva T, Sandweiss BM, Gauvreau K, Lock JE, Powell AJ. 2004. Factors associated with impaired clinical status in long-term survivors of tetralogy of Fallot repair evaluated by magnetic resonance imaging. J Am Coll Cardiol 43:1068-1074.

Grignola JC, Ginés F and Guzzo D. 2006. Comparison of the Tei index with invasive measurements of right ventricular function. Int J Cardiol 113:25-33.

Helbing WA, Niezen RA, Le Cessie S, et al. 1996. Right ventricular diastolic function in children with pulmonary regurgitation after repair of tetralogy of Fallot: Volumetric evaluation by magnetic resonance velocity mapping. J Am Coll Cardiol 28:1827-1835.

Karl TR, Sano S, Pornviliwan S, Mee RBB. 1992. Tetralogy of Fallot: Favorable outcome of nonneonatal transatrial, transpulmonary repair. Ann Thorac Surg 54:903-907.

Kirklin JW, Blackstone EH, Jonas RA, et al. 1992. Morphologic and surgical determinants of outcome events after repair of tetralogy of Fallot and pulmonary stenosis: A two-institutional study. J Thorac Cardiovasc Surg 103:706-723.

Koestenberger M, Nagel B, Avian A, et al. 2012. Systolic right ventricular function in children and young adults with pulmonary artery hypertension secondary to congenital heart disease and tetralogy of Fallot: Tricuspid annular plane systolic excursion (TAPSE) and magnetic resonance imaging data. Congenit Heart Dis 7:250-258.

Lee N, Taylor MD, Banerjee RK. 2015. Right ventricle-pulmonary circulation dysfunction: A review of energy-based approach. Biomed Eng Online 14(suppl 1):S8.

Lozano-Balseiro M, Garcia-Vieites M, Martínez-Bendayán I, et al. 2019. Valve-sparing tetralogy of Fallot repair with intraoperative dilation of the pulmonary valve. Mid-term results. Semin Thorac Cardiovasc Surg 31:828-834.

Mahran Y, Schueler R, Weber M, et al. 2016. Noninvasive model including right ventricular speckle tracking for the evaluation of pulmonary hypertension. World J Cardiol 8:472-480.

Puchalski MD, Williams RV, Askovich B, Minich LL, Mart C, Tani LY. 2007. Assessment of right ventricular size and function: Echo versus magnetic resonance imaging. Congenit Heart Dis 2:27-31.

Rebergen SA, Chin JGJ, Ottenkamp J, Van der Wall EE, de Roos A. 
1993. Pulmonary regurgitation in the late postoperative follow-up of tetralogy of Fallot: Volumetric quantification by MR velocity mapping. Circulation 88(pt 1):2257-2266.

Roberson DA, Cui W. 2007. Right ventricular Tei index in children: Effect of method, age, body surface area, and heart rate. J Am Soc Echocardiogr 20:764-770.

Rudski LG, Lai WW, Afilalo J, et al. 2010. Guidelines for the echocardiographic assessment of the right heart in adult: A report from the American Society of Echocardiography. J Am Soc Echocardiogr 23:700-701.

Schwerzmann M, Samman AM, Salehian O, et al. 2007. Comparison of echocardiographic and cardiac magnetic resonance imaging for assessing right ventricular function in adults with repaired tetralogy of Fallot. Am J Cardiol 99:1593-1597.

Selly JB, Iriart X, Roubertie F, et al. 2015. Multivariable assessment of the right ventricle by echocardiography in patients with repaired tetralogy of Fallot undergoing pulmonary valve replacement: A comparative study with magnetic resonance imaging. Arch Cardiovasc Dis 108:5-15.

Singh GK, Greenberg SB, Yap YS, Delany DP, Keeton BR, Monro JL. 1998. Right ventricular function and exercise performance late after primary repair of tetralogy of Fallot with the transannular patch in infancy. Am J Cardiol 81:1378-1382.

Song B, Qi Q, Liu R, Xing W, Tang H, Li Y. 2015. Clinical value of Tei index in pediatric patients with repaired tetralogy of Fallot. Int J Clin Exp
Med 8:7971-7976.

Su HM, Lin TH, Voon WC, Lee KT, Chu CS, Yen HW, Lai WT, Sheu SH. 2007. Correlation of Tei index obtained from tissue Doppler echocardiography with invasive measurements of left ventricular performance. Echocardiography 24:252-257.

Suzuki J-I, Chang J-M, Caputo GR, Higgins CB. 1991. Evaluation of right ventricular early diastolic filling by cine nuclear magnetic resonance imaging in patients with hypertrophic cardiomyopathy. J Am Coll Cardiol 18:120-126.

Tei C, Dujardin KS, Hodge DO, et al. 1996. Doppler echocardiographic index for assessment of global right ventricular function. J Am Soc Echocardiogr 9:838-847.

Tei C, Dujardin KS, Hodge DO, Kyle RA, Tajik JA, Seward JB. 1996. Doppler index combining systolic and diastolic myocardial performance: Clinical value in cardiac amyloidisis. J Am Coll Cardiol 28:658-664.

Weidemann F, Eyskens B, Mertens L, et al. 2002. Quantification of regional right and left ventricular function by ultrasonic strain rate and strain indexes after surgical repair of tetralogy of Fallot. Am J Cardiol 90:133-138

Yoo BW, Kim JO, Kim YJ, Choi JY, Park HK, Park YH, Sul JH. 2012. Impact of pressure load caused by right venricular outflow tract obstruction on right ventricular volume overload in patients with repaired tetralogy of Fallot. J Thorac Cardiovasc Surg 143:1299-1304. 